\title{
Systemic Administration of MK-801 Protects Against Ischemia-Induced Hippocampal Neurodegeneration in the Gerbil
}

\author{
R. Gill, A. C. Foster, and G. N. Woodruff \\ Merck Sharp and Dohme Research Laboratories, Neuroscience Research Centre, Harlow, Essex, CM20 2QR, UK
}

\begin{abstract}
The neuroprotective effects of MK-801, a noncompetitive antagonist of $\mathrm{N}$-methyl-D-aspartate (NMDA) receptors, were evaluated in models of cerebral ischemia using Mongolian gerbils. Bilateral occlusion of the carotid arteries for a period of $5 \mathrm{~min}$ resulted in a consistent pattern of degeneration of hippocampal CA1 and CA2 pyramidal neurons, which was quantified using an image analyzer. Systemic administration of MK-801 $(0.01-10 \mathrm{mg} / \mathrm{kg}$, i.p.) $1 \mathrm{hr}$ prior to the occlusion caused a dose-dependent protection of the CA1 and CA2 neurons. The $\mathrm{ED}_{50}$ value for neuroprotection by MK-801 was calculated to be $0.3 \mathrm{mg} / \mathrm{kg}$, and at doses $\geq 3 \mathrm{mg} / \mathrm{kg}$ the majority of animals were completely protected against the ischemic insult. Systemic administration of MK-801 (1 or 10 $\mathrm{mg} / \mathrm{kg}$, i.p.) $1 \mathrm{hr}$ prior to unilateral occlusion of the right carotid artery resulted in significant protection against hippocampal neurodegeneration following $\mathbf{1 0 ~} \mathrm{min}$ of occlusion, and increased the survival rate after $30 \mathrm{~min}$ of occlusion. The potent neuroprotective effects of MK-801 in these cerebral ischemia models add further weight to the evidence that NMDA receptors are involved in the mechanism of ischemia-induced neuronal degeneration.
\end{abstract}

Brain ischemia can result from a wide range of disturbances, including cardiovascular disorders and cerebral trauma. Cerebral ischemia both in humans and in experimental animals results in a selective pattern of neuronal degencration within the central nervous system (Levine and Payan, 1966; Pulsinelli and Brierley, 1979; Brierley and Graham, 1984). Investigations into the mechanism of ischemia-induced neurodegeneration and the possible therapeutic amelioration of this process have been pursued for many years (Hossmann, 1982; Kogure et al., 1985). Recent evidence suggests that postischemic neuronal degeneration is caused in part by an overactivity of excitatory amino acid transmitter systems (Jorgensen and Diemer, 1982; Beneviste et al., 1984; Simon et al., 1984; Schwarcz and Meldrum, 1985).

It is hypothesized that ischemia elevates the extracellular concentrations of the excitatory neurotransmitters glutamate and aspartate, which act at specific membrane receptors present on postsynaptic neurons, causing overexcitation and ultimately neuronal death. There is growing evidence in support of this

\footnotetext{
Received Jan. 29, 1987; revised Apr. 22, 1987; accepted Apr. 23, 1987.

We wish to thank Bruce MacLean for technical assistance and Roy Hammans for photographic expertise.

Correspondence should be addressed to Miss R. Gill, Merck Sharp \& Dohme Research I aboratories, Neuroscience Research Centre, Terlings Park, Eastwick Road, Harlow, Essex, CM20 2QR, UK.

Copyright (C) 1987 Society for Neuroscience $0270-6474 / 87 / 103343-07 \$ 02.00 / 0$
}

theory regarding the mechanism of ischemic damage. First, areas of the brain that are most vulnerable to ischemia (hippocampus, cerebral cortex, striatum, and cerebellum) all receive prominent excitatory amino acid transmitter inputs (Fagg and Foster, 1983; Fonnum, 1984). Lesions of these pathways prevent ischemiainduced neuronal damage in the hippocampus (Wieloch et al., 1985a; Onodera et al., 1986) and striatum (Wieloch et al., 1985b). Second, microdialysis measurements in vivo have shown that extracellular concentrations of glutamate and aspartate are increased several-fold in the hippocampus during a pcriod of ischemia (Beneviste et al., 1984; Hagberg et al., 1985). Glutamate and aspartate are "excitotoxic" amino acids (Olney et al., 1971), producing a characteristic "axon-sparing" lesion (Olney, 1980) that is also typical of ischemia-induced hippocampal neurodegeneration (Johansen et al., 1984). Finally, selective excitatory amino acid receptor antagonists have been shown to prevent the neuropathology (Rothman, 1984; Simon et al., 1984) and acute changes in energy metabolism (Hagberg et al., 1986) caused by anoxia and ischemia.

The protection from ischemia-induced neurodegeneration by antagonists of excitatory amino acids, particularly those selective for the NMDA receptor subtype, could indicate the therapeutic use of these compounds in the treatment of human ischemic neuropathologies, such as stroke and cardiac arrest (Schwarcz and Meldrum, 1985). However, the available competitive antagonists are polar compounds that do not readily penetrate the blood-brain barrier, and thus have a low potency when applied systemically (Meldrum, 1985), and in order to demonstrate neuroprotective effects, these substances have to be administered intracranially. MK-801 [(+)-5-methyl-10,11dihydro-5H-dibenzo[a,d]cyclohepten-5,10-imine maleate; Fig. 1] is an orally active anticonvulsant (Clineschmidt et al., 1982) that has recently been shown to be a potent, selective, and noncompetitive antagonist of NMDA receptors (Kemp et al., 1986; Wong et al., 1986). In addition, when administered systemically to rats, MK-801 protects against NMDA-induced neuronal degeneration in the hippocampus or striatum (Foster et al., 1987a). Therefore, we evaluated the ability of systemically administered MK-801 to prevent ischemia-induced neuronal damage. For this purpose we used 2 models of cerebral ischemia in the gerbil.

The Mongolian gerbil is extensively used as a model for cerebral ischemia and infarction (Levine and Payan, 1966; Kahn, 1972) because of its unusual cerebral circulation, which lacks connections between the carotid and vertebrobasilar circulations. Bilateral carotid occlusion causes complete forebrain ischemia in all animals (Crockard et al., 1980; Suzuki et al., 1983a), whereas unilateral occlusion of a common carotid artery results 


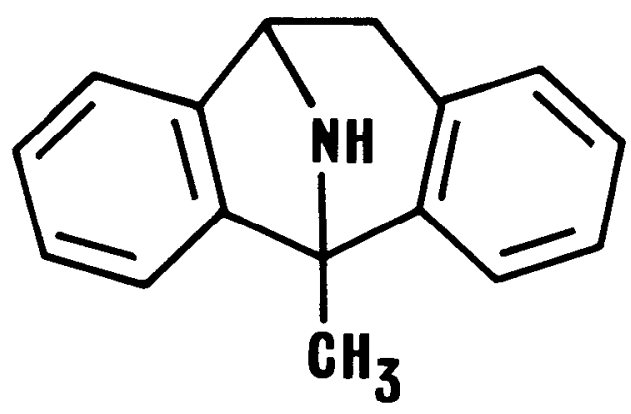

Figure 1. Structure of MK-801 ((+)-5-methyl-10,11-dihydro-5H-dibenzo[a,d]cyclohepten-5,10-imine maleate).

in the development of ischemic injury in some $30-60 \%$ of animals (Harrison et al., 1973; Ito et al., 1975). In this study, the ability of systemically applied MK-801 to prevent ischemiainduced neuronal degeneration has been assessed in both bilateral and unilateral carotid occlusion models. A preliminary account of some of this work has appeared in abstract form (Foster et al., 1987b).

\section{Materials and Methods}

Male and female Mongolian gerbils wcighing 50-80 gm wcrc maintaincd on a $12 \mathrm{hr}: 12 \mathrm{hr}$ light: dark cycle and given access to food and water ad libitum.

Bilateral forebrain ischemia. The animals were anesthetized with a mixture of $2 \%$ halothane, $70 \%$ nitrous oxide, and 30\% oxygen. An anterior midline cervical incision was made, the right and left common carotid arteries were isolated from the vagus nerve and 2 small clips placed on them such that blood flow was completely arrested for a period of $5 \mathrm{~min}$. At the end of the ischemic period, the clips were removed and the patency of the carotid arteries checked by direct visualization, the skin incision was closed with wound clips, and the animals allowed to survive for $4 \mathrm{~d}$. A range of doses of MK-801 $(0.01-10 \mathrm{mg} / \mathrm{kg})$ was administered intraperitoneally $1 \mathrm{hr}$ prior to surgery; untreated animals served as controls.

Unilateral forebrain ischemia. The animals were anesthetized with equithesin, $0.3 \mathrm{ml}$, i.p., an anterior midline cervical incision was made, and the right common carotid artery (RCA) carefully isolated from the vagus nerve. The artery was occluded using a small clip for a period of 10 or $30 \mathrm{~min}$, and, on removal of the clip, restoration of blood flow through the artery was verified visually. The incision was closed with wound clips and the animals allowed to survive for $7 \mathrm{~d}$. MK- 801 was administered at doses of 1 or $10 \mathrm{mg} / \mathrm{kg}$, i.p., $1 \mathrm{hr}$ prior to the occlusion. Control animals were administered saline $(0.2 \mathrm{ml} / 100 \mathrm{gm}$ body weight, i.p.) $1 \mathrm{hr}$ prior to the ischemic insult.

A time course study was also performed to determine the morphology of the neuronal changes accompanying unilateral ischemia; the gerbils were subjected to 10 min occlusion of the RCA and perfused at 1, 2, $5,15,24,48$, and $96 \mathrm{hr}$ following the induction of ischemia.

Histology. The gerbils were anesthetized with equithesin $(0.4 \mathrm{ml}, \mathrm{i} . \mathrm{p}$. and perfused transcardially with $20 \mathrm{ml}$ of $0.9 \%$ saline, followed by 100 $\mathrm{ml}$ of a solution containing $10 \%$ formaldehyde and $5 \%$ sucrose. The brains were removed to a solution of $30 \%$ sucrose and $5 \%$ formaldehyde for 2-5 d. Coronal sections $(40 \mu \mathrm{m})$ were taken through the brain at the level of the hippocampus using a freezing sledge microtome (Leitz), and stained with cresyl violet (Nissl stain).

Quantitative assessment of ischemia-induced neuropathology. In the bilateral carotid occlusion experiments, the area of neuronal degeneration within the hippocampus was assessed using a Cambridge Instruments image analyzer. For each animal, measurements were made from both hippocampi in 3 coronal sections corresponding to $1.5,1.7$, and $1.9 \mathrm{~mm}$ caudal to bregma. Using the image analyzer, a line was drawn in each hippocampal plane, encircling the degenerating CA1 and CA2 pyramidal cell area (both cell body and dendritic layers) from the hippocampal fissure to the alveus (Fig. 2). The pattern of hippocampal neurodegeneration following ischemia, with or without MK-801 pretreatment, consisted of discrete areas of neuronal loss (see below), making this type of analysis feasible. This area was summed for the 3 sec- tions, which gave the total area of degeneration in 6 hippocampal planes. The areas from different animals within each experimental group are expressed as the mean \pm SEM, and nonparametric statistical evaluation included the Kruskal-Wallis analysis of variance and a Mann-Whitney $U$ test comparing MK-801-treated groups with the controls.

For the $10 \mathrm{~min}$ unilateral carotid occlusion experiments, brain sections were viewed under the light microscope and the animals divided into "damage" or "no damage" groups on the basis of their hippocampal morphology. This was carried out under blind conditions by 3 independent observers, whose evaluations agreed completely. For the 30 min RCA occlusion experiments, the number of animals that survived the $7 \mathrm{~d}$ period was counted. The statistical significance of the differences between MK-801-treated animals and controls was assessed using Fisher's exact probability test (Siegel, 1956).

\section{Results}

\section{Bilateral common carotid artery occlusion}

Complete forebrain ischemia for a period of $5 \mathrm{~min}$ resulted in a model that showed consistent neuronal degeneration in each experimental animal. The pattern of neurodegeneration involved virtually all pyramidal neurons in the CA1 and CA2 areas of both hippocampi (Fig. $3 A$ ); no other neuronal degeneration was apparent in any other forebrain region. Assessing the hippocampal damage by measuring the affected area of the $\mathrm{CA} 1$ and CA2 region proved to be a convenient and highly consistent method. Thus, in 12 control animals that were all severely affected, the area of degeneration was $7.30 \pm 0.32 \mathrm{~mm}^{2}$ (mean \pm SEM), indicating that the SEM was $<5 \%$ of the mean value. Administration of MK-801, i.p., $1 \mathrm{hr}$ prior to bilateral occlusion resulted in a dose-dependent decrease in the area of neuronal degeneration (Table 1). The lowest dose of MK-801 producing significant protection was $0.1 \mathrm{mg} / \mathrm{kg}$, and the $\mathrm{ED}_{50}$ value for neuroprotection against complete forebrain ischemia was calculated to be $0.3 \mathrm{mg} / \mathrm{kg}$. Following doses of MK- $801 \geq 3$ $\mathrm{mg} / \mathrm{kg}$, the majority of animals showed complete protection against ischemia-induced neuronal loss (Fig. 3C). At the higher doses of MK-801 $(1-10 \mathrm{mg} / \mathrm{kg})$ the animals were ataxic; however, they did not appear sedated, since signs of motor stimulation were apparent. At lower doses $(\leq 0.3 \mathrm{mg} / \mathrm{kg})$, the pattern of damage consisted mainly of patches of degenerated hippocampal neurons (Fig. $3 B$ ), indicating partial protection in individual animals; no overt behavioral effects were observed.

\section{Unilateral RCA occlusion}

Unilateral ischemia for a period of $10 \mathrm{~min}$ resulted in neuronal degeneration in the ipsilateral forebrain in $60 \%$ of the control animals. The neurodegeneration was confined to the hippocampal formation, and the pyramidal cells in the CA1 and CA2 areas were the neurons most vulnerable to ischemia (Fig. 4A). This finding is in agreement with previous reports (Kahn, 1972; Harrison et al., 1973; Ito et al., 1975), although in 2 out of 12 animals, CA3 and CA4 area pyramidal cells were additionally involved. Pretreatment with MK-801 at doses of 1 or $10 \mathrm{mg} /$ $\mathrm{kg}$, i.p., $1 \mathrm{hr}$ prior to $10 \mathrm{~min}$ RCA occlusion reduced the ipsilateral neuronal damage (Table 2a). Thus, following $10 \mathrm{~min}$ of unilateral ischemia, $60 \%$ of the control animals showed hippocampal damage which was significantly reduced to 20 and $15 \%$ with 1 and $10 \mathrm{mg} / \mathrm{kg}$ of MK-801, respectively.

The time course of the morphological changes occurring within the hippocampus following $10 \mathrm{~min}$ of unilateral RCA occlusion was investigated (Table 3). During initial periods of reperfusion (up to $15 \mathrm{hr}$ ), few signs of overt neuronal degeneration were evident; the changes that occurred were characterized by swollen, light-staining neurons, particularly in areas CA1, CA2, 

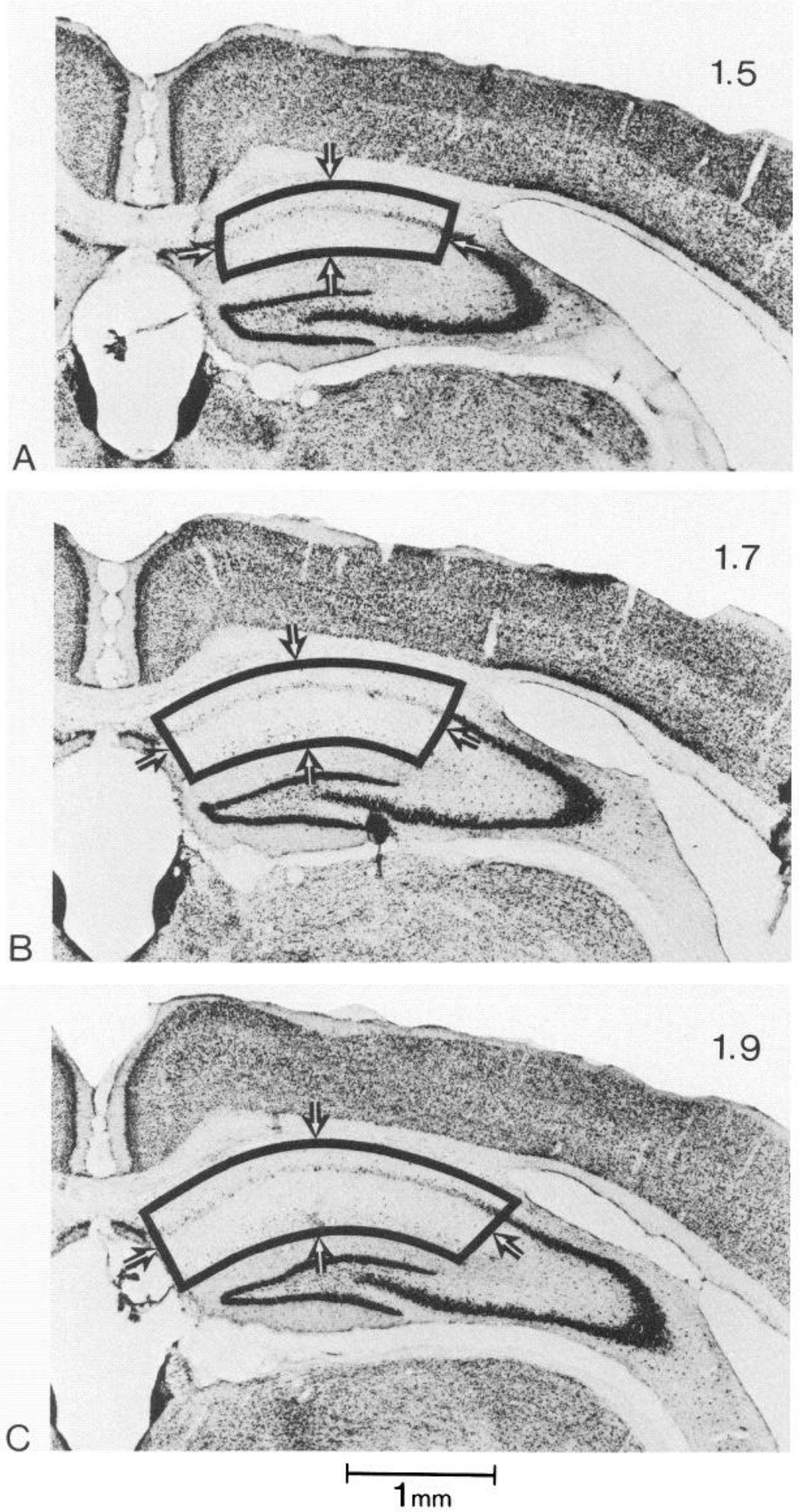

Figure 2. Light micrographs of $40 \mu \mathrm{m}$ coronal sections of the cresyl violetstained right hippocampus from a typical untreated gerbil subjected to $5 \mathrm{~min}$ of bilateral ischemia. Solid line and arrows illustrate the area of neuronal degeneration that was measured in the 3 coronal sections corresponding to 1.5 $(A), 1.7(B)$, and $1.9(C) \mathrm{mm}$ caudal to bregma. The line drawn encircles the degenerating CA1 and CA2 pyramidal neurons, including cell bodies and dendrites, i.e., the total area of neurodegeneration from the hippocampal fissure to the alveus. and CA3. From $24 \mathrm{hr}$ onwards, degeneration of CA1 and CA2 pyramidal neurons occurred, which was essentially complete at $4 \mathrm{~d}$.

A 30 min period of RCA occlusion resulted in the death of $50 \%$ of the control gerbils within the $7 \mathrm{~d}$ experimental period (Table 2b). Histological examination of the brains of the 10 survivors revealed a varied pattern of neuronal degeneration. In 3 animals the damage was restricted to loss of CA1 and CA2 pyramidal neurons, and total hippocampal necrosis (Fig. $4 B$ ) occurred in 2 animals, accompanied by neuronal damage in the cerebral cortex and striatum; there was no hippocampal damage seen in the remaining 5 animals. MK-801 administered $1 \mathrm{hr}$ prior to $30 \mathrm{~min}$ occlusion of the RCA at doses of 1 or $10 \mathrm{mg} /$ $\mathrm{kg}$ increased the number of animals that survived the ischemic insult. For the control animals, the rate of survival was $50 \%$, which was increased to 75 and $90 \%$ with doses of 1 and $10 \mathrm{mg} /$ 
A

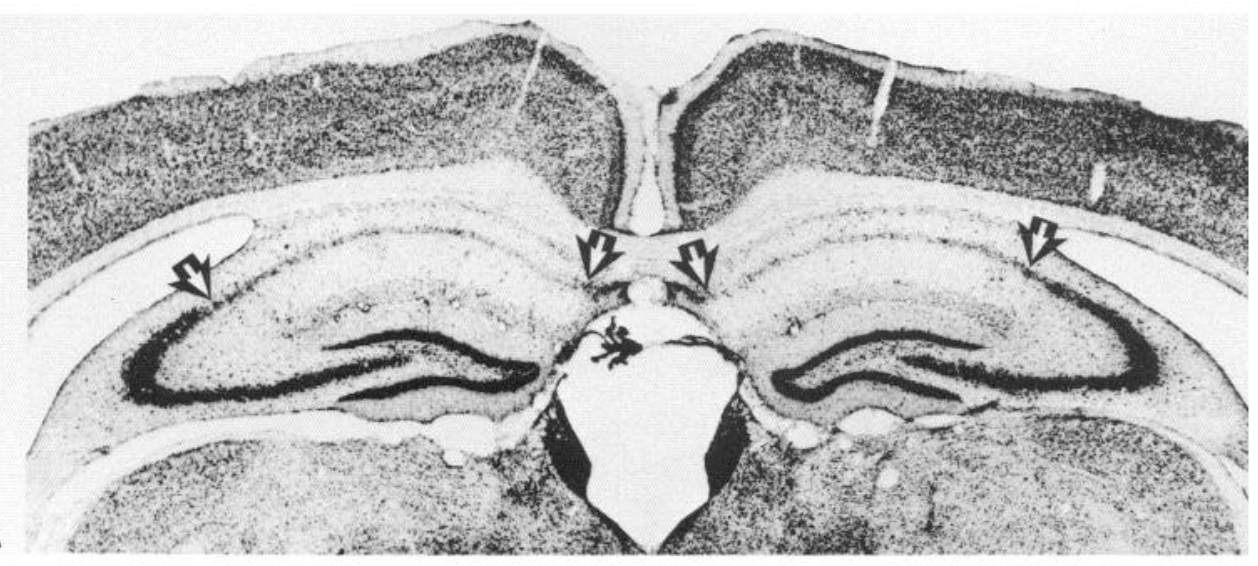

Figure 3. Protection by MK-801 in a dose-dependent manner of hippocampal neurodegeneration induced by $5 \mathrm{~min}$ of bilateral ischemia. The MK-801 was administered $1 \mathrm{hr}$ prior to carotid occlusion. Light micrographs of $40 \mu \mathrm{m}$ coronal sections, stained with cresyl violet, showing the hippocampal area 4 $\mathrm{d}$ following the ischemic insult. $A$, Pattern of degeneration of pyramidal cells in areas CA1 and CA2 (between arrows) in the hippocampi of a control gerbil. $B$, Partial protection seen with a low dose of MK-801 $(0.3 \mathrm{mg} / \mathrm{kg})$; the area of degeneration is shown between the arrows. $C$, Complete protection of pyramidal cells in the hippocampi of a gerbil treated with $3 \mathrm{mg} / \mathrm{kg}$ of MK- 801 .
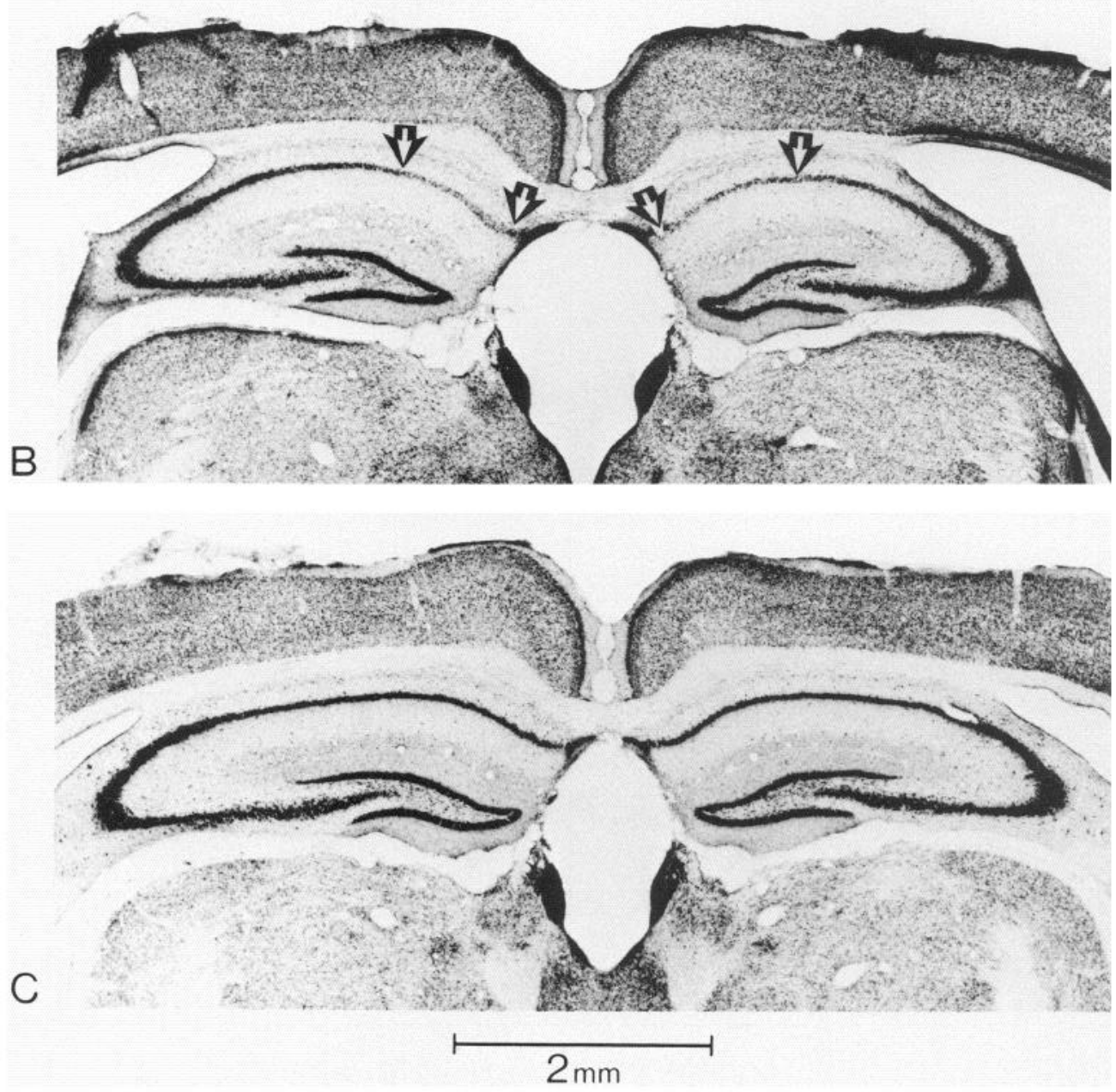

$\mathrm{kg}$ of MK-801, respectively, an effect that was significant at the $10 \mathrm{mg} / \mathrm{kg}$ dose (Table $2 \mathrm{~b}$ ).

\section{Discussion}

The results described in this paper demonstrate that systemically administered MK-801 prevents ischemia-induced neuronal degeneration and death in the gerbil. A single dose of MK-801 given intraperitoneally $1 \mathrm{hr}$ prior to the occlusion was sufficient to protect against ischemia-induced neuropathology.

Bilateral common carotid artery occlusion provides a model that results in consistent and reproducible damage of the CA1 and CA2 pyramidal cells in all animals. This area of neuronal degeneration can be evaluated in individual animals quite accurately using the method described above, and the consistency of the neurodegeneration allowed the discrimination of small protective effects of MK- 801 . Thus, the data obtained from the bilateral carotid occlusion model permitted an accurate assessment of the potency of MK-801. The unilateral carotid occlusion model was used to assess neuroprotection against a more severe ischemic insult. However, only $50-60 \%$ of control animals displayed either neurodegeneration (10 min occlusion period) or death ( 30 min occlusion period). Therefore, the protective effects of MK- 801 were assessed by simply grouping the animals into 2 categories, i.e., "damage" or "no damage" for the $10 \mathrm{~min}$ 

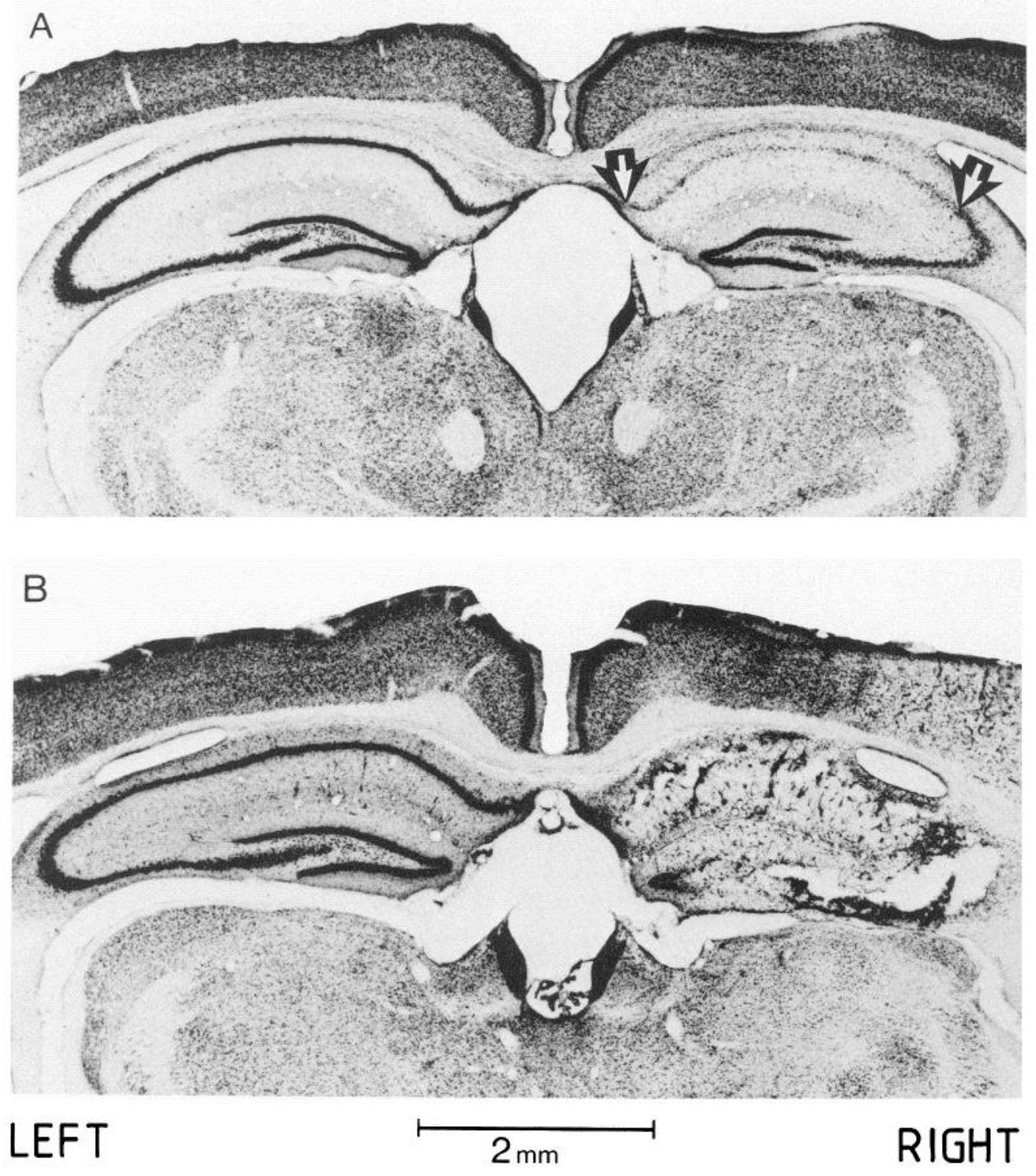

Figure 4. Light micrographs of $40 \mu \mathrm{m}$ coronal sections stained with cresyl violet showing the morphological changes that occurred following unilateral ischemia in control gerbils. $A$, Typical pattern of hippocampal neurodegeneration in the pyramidal $\mathrm{CA} 1$ and $\mathrm{CA} 2$ areas (between arrows) $7 \mathrm{~d}$ after a 10 min period of RCA occlusion. $B$, Extensive neuronal degeneration $7 \mathrm{~d}$ after $30 \mathrm{~min}$ of RCA occlusion. The ipsilateral hemisphere shows almost total necrosis of the hippocampus, with cortical neurons also showing degeneration. There are no changes evident on the contralateral side in either animal.

occlusions and "death" or "survival" for the 30 min occlusions; this method is incapable of detecting small protective effects without the use of prohibitively large numbers of animals.

In the bilateral carotid artery occlusion model, significant protection was obtained with $0.1 \mathrm{mg} / \mathrm{kg}$ of MK-801 and doses $\geq 3 \mathrm{mg} / \mathrm{kg}$ caused complete protection in a majority of the animals. MK- 801 in the unilateral ischemia model, at doses of 1 and $10 \mathrm{mg} / \mathrm{kg}$, produced significant protection against the hippocampal neurodegeneration following 10 min occlusion. However, in the more severe unilateral ischemia involving a $30 \mathrm{~min}$ period of occlusion, a significant increase in the number of survivors was seen only with the $10 \mathrm{mg} / \mathrm{kg}$ dose, although the 1 $\mathrm{mg} / \mathrm{kg}$ dose of MK- 801 also showed a trend towards significance. Thus, it appears that higher doses of MK-801 are required to counteract severe ischemic insults, which may be a consequence of prolonged increases of extracellular concentrations of excitotoxic amino acids.

In electrophysiological experiments, $\mathrm{MK}-801$ is a potent and selective antagonist of NMDA receptors (Kemp et al., 1986; Wong et al., 1986). MK-801 is also a selective antagonist of
Table 1. Neuroprotective action of various doses of MK-801 given intraperitoneally $1 \mathrm{hr}$ prior to bilateral carotid artery occlusion for a period of $5 \mathrm{~min}$ in gerbils

\begin{tabular}{llll}
$\begin{array}{l}\text { Dose of } \\
\text { MK-801 } \\
(\mathrm{mg} / \mathrm{kg})\end{array}$ & $n$ & $\begin{array}{l}\text { Area of neuronal } \\
\text { degeneration }\left(\mathrm{mm}^{2}\right)\end{array}$ & $\begin{array}{l}\text { No. of } \\
\text { animals } \\
\text { showing } \\
\text { no damage }\end{array}$ \\
\hline Control & 12 & $7.3 \pm 0.32$ & 0 \\
0.01 & 9 & $6.5 \pm 0.88$ & 1 \\
0.03 & 10 & $5.3 \pm 0.99$ & 1 \\
0.1 & 10 & $4.9 \pm 0.89^{*}$ & 2 \\
0.3 & 10 & $4.9 \pm 0.78^{* *}$ & 1 \\
1 & 10 & $1.5 \pm 0.58^{* *}$ & 5 \\
3 & 10 & $0.9 \pm 0.51^{* *}$ & 7 \\
10 & 10 & $0.8 \pm 0.45^{* *}$ & 7
\end{tabular}

Values are means \pm SEM ( $n$ animals) of the areas of degeneration (in $\left.\mathrm{mm}^{2}\right)$ (involving, in each animal, 6 hippocampal planes from 3 coronal sections), measured $4 \mathrm{~d}$ after artery occlusion. Kruskal-Wallis analysis of variance, $H=42.20(p \leq$ $0.0001)$. Asterisks, significant difference when compared with control animals at the $0.05\left(^{*}\right)$ and $0.01\left(^{(*)}\right.$ level using the Mann-Whitney $U$ test. 
Table 2. Effect of pretreatment with MK-801 following unilateral occlusion of the right carotid artery of the gerbil

\begin{tabular}{lllc} 
& $\begin{array}{c}\text { Control } \\
(n=20)\end{array}$ & \multicolumn{2}{c}{ Dose of MK-801 mg/kg } \\
\cline { 4 - 4 } & & $1(n=20)$ & $10(n=20)$ \\
\hline a. 10 min occlusion & 12 & 4 & 3 \\
No. of animals showing damage & 8 & 16 & 17 \\
No. of animals showing no damage & & $(p=0.02)$ & $(p=0.01)$ \\
& 10 & 15 & 18 \\
b. 30 min occlusion & 10 & 5 & 2 \\
No. of animals surviving & & $(p=0.20)$ & $(p=0.02)$
\end{tabular}

Animals were assessed for histological damage in CA1 hippocampal neurons $7 \mathrm{~d}$ after artery occlusion. $n=$ Number of animals. Figures in parentheses denote significance values when compared with control animals, determined using Fisher's exact probability test.

NMDA-induced neurodegeneration in vivo, and at doses up to $10 \mathrm{mg} / \mathrm{kg}$ does not decrease the neurotoxic effects of kainic acid (Foster et al., 1987a). The high potency of MK-801 $\left(\mathrm{ED}_{50}=0.3\right.$ $\mathrm{mg} / \mathrm{kg}$ ) in preventing ischcmia-induccd neuronal degeneration in the gerbil, therefore, suggests that this effect is mediated by a selective blockade of NMDA receptors. Thus, the remarkable ability of MK-801 to completely prevent ischemia-induced neuronal damage suggests that the NMDA receptor subtype is the key receptor involved in postischemic excitotoxic neurodegeneration.

The neurons in the CA1 and CA2 pyramidal area of the hippocampus are the most vulnerable to global ischemia in both human and animal brains (Brierley and Graham, 1984; ZolaMorgan et al., 1986). This was evident in the present series of experiments since, when neurodegeneration was observed, it invariably included CA 1 and CA2 pyramidal cell damage, with the additional involvement of other hippocampal neurons and other brain regions in some animals only. Autoradiographic

Table 3. Time course study of ischemic cell changes occurring in the hippocampus following $10 \mathrm{~min}$ occlusion of the right carotid artery of the gerbil

\begin{tabular}{lllll}
$\begin{array}{l}\text { Time } \\
\text { after } \\
\text { isch- } \\
\text { emia } \\
\text { (hr) }\end{array}$ & $\begin{array}{l}\text { No. of } \\
\text { animals } \\
\text { showing } \\
\text { no } \\
\text { changes }\end{array}$ & \multicolumn{4}{l}{ Hippocampal pyramidal neuron morphology } \\
\cline { 2 - 5 } CA1 & CA2 & CA3 \\
\hline 1 & 4 & $+(2)$ & $+(4)$ & $+(3)$ \\
2 & 5 & & $+(5)$ & $+(2)$ \\
5 & 4 & & $+(6)$ & $+(1)$ \\
15 & 3 & & $+(6)$ & $+(4)$ \\
24 & 1 & $+(4)$ & $+(4)$ & $+(2)$ \\
& & $++(1)$ & $++(3)$ & \\
& & $+++(1)$ & $+++(1)$ & \\
48 & 3 & $+(3)$ & $+(1)$ & $+(1)$ \\
& & $++(1)$ & $++(1)$ & \\
& & $+++(2)$ & $+++(4)$ & $+(5)$ \\
96 & 2 & $+(1)$ & $+(3)$ & $++(2)$ \\
& & $+++(5)$ & $++(1)$ &
\end{tabular}

Experiments were performed as described in the text. Hippocampal pyramidal cell morphology was scored as follows: + , swollen cells lighter stained; ++ , some neurons degenerating; +++ , all neurons degenerating. Figures in parentheses indicate the number of gerbils from a group of 10 showing these changes. studies have demonstrated that the dendritic layers of the CA1 and CA2 neurons of the rodent hippocampus possess the highest density of NMDA receptors in the brain (Monaghan and Cotman, 1985). The CA1/CA2 pyramidal neurons may owe their selective vulnerability in ischemia to a high density of NMDA receptors on their dendrites.

The detailed mechanisms that underlie ischemia-induced degeneration of hippocampal neurons have yet to be clarified. The data from the time course study of hippocampal morphology following unilateral carotid occlusion indicate a delayed $(>24$ hr) degeneration of CA1 and CA2 neurons. This phenomenon has been observed by others and termed a "maturation phenomenon" (Ito et al., 1975) or "delayed neuronal death" (Kirino, 1982). CA1 pyramidal neurons are known to degenerate as a result of prolonged seizure activity (Brierley, 1976), and gerbils are renowned for their susceptibility to seizures in response to a variety of stimuli, such as handling, change in environment, or physical stimulation (Thiessen et al., 1968; Cox and Lomax, 1976). Thus, it could be argued that the delayed CA1 and CA2 neuronal degeneration that follows transient ischemia might be due to seizure activity during the postischemic period. The $\mathrm{ED}_{50}$ for MK-801 against ischemia-induced hippocampal neurodegeneration $(0.3 \mathrm{mg} / \mathrm{kg})$ is similar to its anticonvulsant $\mathrm{ED}_{50}$ value in a variety of seizure models (Clineschmidt et al., 1982) and against NMDA (340 mg/kg, s.c.)-induced convulsions in mice $\left(\mathrm{ED}_{50}=0.3 \mathrm{mg} / \mathrm{kg}\right.$, i.p.; unpublished observations). However, it appears unlikely that seizures are the cause of ischemia-induced neuronal damage in the gerbil. Thus, Cohn (1979) reported that the gerbil brain is electrically silent during ischemia, and epileptiform activity, if present, does not arise from the ischemic brain itself during ischemia. Further evidence has shown that, using extracellular recordings of $\mathrm{CA} 1$ neuronal activity in the postischemic period, there is an increase in cell firing but no epileptiform events are seen (Suzuki et al., 1983b) Finally, Donadio et al. (1982) have demonstrated that, in a given population of gerbils, there is no correlation between seizure-prone and stroke-prone individuals. In this study and in a previous report (Suzuki et al., 1983a), no overt signs of seizure activity were seen during or following the ischemic insult in gerbils that underwent a 5 or $10 \mathrm{~min}$ period of occlusion. Recent evidence indicates that NMDA receptors may mediate epileptiform activity in CAl pyramidal neurons (Dingledine, 1986). Therefore, it would seem more likely that the similarity between the $\mathrm{ED}_{50}$ values for MK-801 against seizures and for ischemia-induced 
neuronal degeneration simply reflects the doses required to block NMDA receptors and does not imply that seizures are the cause of ischemia-induced neuronal death.

This study indicates that MK-801 has shown activity in preventing ischemia-induced neuronal degeneration in the gerbil, and thus adds weight to the growing evidence that NMDA receptors are fundamentally involved in this type of neuropathology. At the present time, MK- 801 is the best candidate for potential clinical testing among known NMDA antagonists because of its potency and ready penetration of the blood-brain barrier.

\section{References}

Beneviste, H., J. Drejer, A. Schousboe, and N. H. Diemer (1984) Elevation of extracellular concentrations of glutamate and aspartate in rat hippocampus during transient cerebral ischaemia monitored by intracerebral microdialysis. J. Neurochem. 43: 1369-1374.

Brierley, J. B. (1976) Cerebral hypoxia. In Greenfield's Neuropathology, W. Blackwood and J. A. N. Corsellis, eds., pp. 43-85, Edward Arnold, London.

Brierley, J. B., and D. I. Graham (1984) Hypoxia and vascular disorders of the central nervous system. In Greenfield's Neuropathology, J. H. Adams, J. A. N. Corsellis, and L. W. Duchen, eds., pp. 125205, Edward Arnold, London.

Clineschmidt, B. V., G. E. Martin, and P. R. Bunting (1982) Anticonvulsant activity of MK-801, a substance with potent anticonvulsant, central sympathomimetic and apparent anxiolytic properties. Drug Dev. Res. 2: 123-134.

Cohn, R. (1979) Convulsive activity in gerbils subjected to cerebral ischaemia. Exp. Neurol. 65: 391-397.

Cox, B., and P. Lomax (1976) Brain amines and spontaneous epileptic scizures in the Mongolian gerbil. Pharmacol. Biochem. Behav. 4:263267.

Crockard, A., F. Bannotti, A. T. Hunstock, R. D. Smith, R. J. Harris, and L. Symon (1980) Cerebral blood flow and edema following carotid occlusion in the gerbil. Stroke 11: 494-498.

Dingledine, R. (1986) NMDA receptors: What do they do? Trends Neurosci. 9: 47-49.

Donadio, M. F., P. B. Kozlowski, H. Kaplan, H. M. Wisniewski, and J. Mejkowski (1982) Brain vasculative and induced ischaemia in seizure-prone and non-seizure-prone gerbils. Brain Res. 234: 263273.

Fagg, G. F., and A. C. Foster (1983) Amino acid transmitters and their pathways in the mammalian central nervous system. Neuroscience 9: 701-719.

Fonnum, F. (1984) Glutamate: A neurotransmitter in mammalian brain. J. Neurochem. 42:1-11.

Foster, A. C., R. Gill, J. A. Kemp, and G. N. Woodruff (1987a) Systemic administration of MK-801 prevents $N$-methyl-D-aspartate-induced neuronal degeneration in rat brain. Neurosci. Lett. 76: 307311.

Foster, A. C., R. Gill, L. L. Iversen, and G. N. Woodruff (1987b) Systemic administration of MK-801 protects against ischaemia-induced hippocampal neurodegeneration in the gerbil. Br. J. Pharmacol. Proc. (Suppl.) 90: 9P.

Hagberg, H., A. Lehmann, M. Sandberg, B. Nystrom, I. Jacobson, and A. Hamberger (1985) Ischaemia-induced shift of inhibitory and excitatory amino acids from intra- to extracellular compartments. J. Cereb. Blood Flow Metab. 5: 413-419.

Hagberg, H., P. Anderson, S. Butcher, M. Sandberg, A. Lehmann, and A. Hamberger (1986) Blockade of $N$-methyl-D-aspartate-sensitive acidic amino acid receptors inhibits ischaemia-induced accumulation of purine catabolites in the rat striatum. Neurosci. Lett. 68: 311-316.

Harrison, M. J. G., D. Brownhill, P. D. Lewis, and R. W. R. Russell (1973) Cerebral edema following carotid artery ligation in the gerbil. Arch. Neurol. 28: 389-391.

Hossmann, K. A. (1982) Treatment of cerebral ischaemia. J. Cereb. Blood Flow Metab. 2: 275-297.

Ito, U., M. Spatz, J. T. Walker, Jr., and I. Klatzo (1975) Experimental cerebral ischaemia in Mongolian gerbil. Light microscopic observations. Acta Neuropathol. 32: 209-223.

Johansen, F. F., M. B. Jorgensen, D. K. J. Ekstrom von Lubitz, and N.
H. Diemer (1984) Selective dendrite damage in hippocampal CA1 stratum radiatum with unchanged axon ultrastructure and glutamate uptake after transient cerebral ischaemia in the rat. Brain Res. 291: 373-377.

Jorgensen, M. B., and N. H. Diemer (1982) Selective neuron loss after cerebral ischaemia in the rat: Possible role of transmitter glutamate. Acta Neurol. Scand. 66: 536-546.

Kahn, K. (1972) The natural course of experimental cerebral infarction in the gerbil. Neurology 22:510-515.

Kemp, J. A., T. Priestly, and G. N. Woodruff (1986) MK-801, a novel, orally active anticonvulsant is a potent, non-competitive $N$-methylD-aspartate-receptor antagonist. Br. J. Pharmacol. Proc. (Suppl.) 89: $535 \mathrm{P}$.

Kirino, T. (1982) Delayed neuronal death in the gerbil hippocampus following ischaemia. Brain Res. 239: 57-69.

Kogure, K., K. A. Hossmann, B. K. Siesjo, and F. A. Welsh, eds. (1985) Progress in Brain Research, vol. 63, Elsevier, New York.

Levine, S., and H. Payan (1966) Effects of ischaemia and other procedures on the brain and retina of the gerbil (Meriones unguiculatus). Exp. Neurol. 16: 255-262.

Meldrum, B. (1985) Possible therapeutic applications of antagonists of excitatory amino acid neurotransmitters. Clin. Sci. 68: 113-122.

Monaghan, D. T., and C. W. Cotman (1985) Distribution of $N$-methylD-aspartate-sensitive $\mathbf{L}-\left[{ }^{3} \mathrm{H}\right]$ glutamate binding sites in rat brain. $\mathbf{J}$. Neurosci. 5: 2909-2919.

Olney, J. W. (1980) Excitotoxic mechanisms of neurotoxicity. In $E x$ perimental and Clinical Neurotoxicology, P. S. Spencer and H. H. Schaumberg, eds., pp. 272-294, Williams and Wilkins, Baltimore, MD.

Olney, J. W., O. L. Ho, and V. Rhee (1971) Cytotoxic effects of acidic and sulphur containing amino acids on the infant mouse central nervous system. Exp. Brain. Res. 14: 61-76.

Onodera, H., G. Sato, and K. Kogure (1986) Lesions to Schaffer collaterals prevent ischaemic death of CA1 pyramidal cells. Neurosci. Lett. 68: 169-174.

Pulsinelli, W. A., and J. B. Brierley (1979) A new model of bilateral hemispheric ischaemia in the unanesthetized rat. Stroke 10:267-272.

Rothman, S. (1984) Synaptic release of excitatory amino acid neurotransmitter mediates anoxic neuronal death. J. Neurosci. 4: 18841891.

Schwarcz, R., and B. Meldrum (1985) Excitatory amino acid antagonists provide a therapeutic approach to neurological disorders. Lancet $2: 140-143$.

Siegel, S. (1956) Nonparametric Statistics for the Behavioral Sciences, pp. 96-104, McGraw-Hill, New York

Simon, R. P., J. H. Swan, T. Griffith, and B. S. Meldrum (1984) Blockade of $N$-methyl-D-aspartate receptors may protect against ischaemic damage in the brain. Science 226: 850-852.

Suzuki, R., T. Yamaguchi, T. Kirino, F. Orzi, and I. Klatzo (1983a) The effects of 5-minute ischaemia in Mongolian gerbils: I. Bloodbrain barrier, cerebral blood flow, and local cerebral glucose utilization changes. Acta Neuropathol. (Berl.) 60: 207-216.

Suzuki, R., T. Yamaguchi, L. Choh-Luh, and I. Klatzo (1983b) The effects of 5-min ischaemia in Mongolian gerbils: II. Changes of spontaneous neuronal activity in cerebral cortex and CAl sector of hippocampus. Acta Neuropathol. (Berl.) 60: 217-222.

Thiessen, D. D., G. Lindzey, and H. C. Friend (1968) Spontaneous seizures in the Mongolian gerbil (Meriones unguiculatus). Psychonomic. Sci. 11: 227-228.

Wieloch, T., O. Lindrall, P. Blomqvist, and F. Gage (1985a) Evidence for amelioration of ischaemic neuronal damage in the hippocampal formation by lesions of the perforant path. Neurol. Res. 7: 24-26.

Wieloch, T., B. Engelson, G. Wcstcrberg, and R. Aucr (1985b) Lesions of the glutamatergic cortico-striatal projections in the rat ameliorate hypoglycemic brain damage in the striatum. Neurosci. Lett. 58: 2530.

Wong, E. H. F., J. A. Kemp, T. Priestly, A. R. Knight, G. N. Woodruff, and L. L. Iversen (1986) The anticonvulsant MK-801 is a potent $N$-methyl-D-aspartate antagonist. Proc. Natl. Acad. Sci. 83: 7104 7108.

Zola-Morgan, S., L. R. Squire, and D. G. Amaral (1986) Human amnesia and the medial temporal region: Enduring memory impairment following a bilateral lesion limited to field CA1 of the hippocampus. J. Neurosci, 6: 2950-2967. 